\title{
Comparison of 4 label-based immunochromatographic assays for the detection of Escherichia coli 0157:H7 in milk
}

\author{
Kai Luo, ${ }^{, 1}$ Liming Hu, ${ }^{11}$ Qi Guo, ${ }^{*}$ Chenghui Wu, ${ }^{*}$ Songsong Wu, ${ }^{*}$ Daofeng Liu, $†$ Yonghua Xiong, ${ }^{*}$ \\ and Weihua Lai ${ }^{* 2}$ \\ *State Key Laboratory of Food Science and Technology, Nanchang University, Nanchang 330047, China \\ †Jiangxi Province Centers for Disease Control and Prevention, Nanchang 330096, China
}

\begin{abstract}
Immunochromatographic assays (ICA) are widely used to detect pathogens. In this study, we used traditional gold nanoparticles (GNP), quantum dots (QD), fluorescent nanoparticles (FNP), and europium (Eu) (III) chelate nanoparticles (EuNP) as ICA labels. We first compared the ability of the 4 ICA test strips to quantitatively detect Escherichia coli O157:H7 in milk. We then optimized various parameters influencing the ICA. The sensitivity to E. coli O157:H7 of the GNPICA, QD-ICA, FNP-ICA, and EuNP-ICA was $2.5 \times$ $10^{4}, 5 \times 10^{3}, 1.0 \times 10^{3}$, and $5.0 \times 10^{2} \mathrm{cfu} \mathrm{mL}^{-1}$, respectively. The EuNP-ICA exhibited the highest sensitivity. The amounts of monoclonal antibodies $(\mathrm{mAb})$ per GNP-ICA, QD-ICA, FNP-ICA, and EuNP-ICA test strip were $0.16,0.37,0.04$, and $0.10 \mu \mathrm{g}$, respectively. The corresponding coefficients of variation were 7.4 to $15.8 \%, 10.4$ to $18.6 \%, 2.7$ to $7.8 \%$, and 6.9 to $10.5 \%$, respectively. The FNP-ICA required the least mAb per test strip and had the best coefficient of variation. The linear ranges of GNP-ICA, QD-ICA, FNP-ICA, and EuNP-ICA were $1.0 \times 10^{4}$ to $1.0 \times 10^{6}, 2.5 \times 10^{3}$ to 1.0 $\times 10^{6}, 2.5 \times 10^{2}$ to $2.5 \times 10^{5}$, and $2.5 \times 10^{2}$ to $2.5 \times 10^{5}$ cfu $\mathrm{mL}^{-1}$, respectively. The FNP-ICA and EuNP-ICA had wider linear ranges than GNP-ICA and QD-ICA. Additionally, the FNP-ICA and EuNP-ICA showed better tolerance than GNP-ICA and QD-ICA in the milk samples. The FNP-ICA and EuNP-ICA showed remarkable potential for detection of pathogens in milk.
\end{abstract} Key words: gold nanoparticle, quantum dot, fluorescent nanoparticle, Eu (III) chelate nanoparticle

\section{INTRODUCTION}

Pathogens are the major etiological agents of diseases related to dairy product consumption, posing great

Received January 5, 2017

Accepted March 8, 2017.

${ }^{1}$ These authors contributed equally to this study.

${ }^{2}$ Corresponding author: talktolaiwh@163.com threat to public health (Guimarães et al., 2017; Taponen et al., 2017). More than $90 \%$ of the diseases related to dairy product consumption are caused by bacteria (Franco et al., 2013). The World Health Organization has emphasized the need to control and prevent the spread of pathogens associated with food consumption (World Health Organization, 2015). Traditional culture and colony-counting methods (Brichta-Harhay et al., 2007) are standard approaches for detecting pathogens, but these methods are inconvenient, because they require considerable time and effort and highly trained personnel. A simple and sensitive pathogen detection method is needed to ensure food safety. The feasibility of methods such as PCR (Bian et al., 2015), surface plasmon resonance (Wang et al., 2013), gene chip (Jiawang et al., 2016), electrochemical strategy (Barreiros dos Santos et al., 2013), and ELISA (Shan et al., 2016) for detecting pathogens has been extensively studied. These methods are more sensitive than traditional detection approaches, but their complex procedures, expensive equipment, and extensive analysis time also restrict their application in the onsite detection of pathogens.

The immunochromatographic assay (ICA) is a rapid, simple, sensitive, specific, user-friendly, affordable detection method (Ju et al., 2016). Gold nanoparticles (GNP) are widely used as labels to detect pathogens, including Vibrio parahaemolyticus (Liu et al., 2016), Escherichia coli O157:H7 (Zhang et al., 2015), Salmonella typhi (Preechakasedkit et al., 2012), and Listeria monocytogenes (Ueda et al., 2013). However, traditional GNP-based ICA (GNP-ICA) are limited by their relatively low sensitivity (Liu et al., 2011). Novel ICA based on photoluminescent nanoparticles have been developed to improve sensitivity using quantum dots (QD; Xu et al., 2013; Morales-Narváez et al., 2015), fluorescent nanoparticles (FNP; Zhang et al., 2017), and europium (III) chelate nanoparticles (EuNP; Zhang et al., 2014a) as labels to detect pathogens. The advantages of QD are broad adsorption, size-tunable emission in the visible-near infrared range, high photostability, and strong luminescence (Hildebrandt et al., 
2017). The advantages of FNP are high fluorescence intensity and photostability (Zhou et al., 2014). The advantages of EuNP are excellent photoluminescence properties, including high emission fluorescence intensity, large Stokes shift, sharp emission profile, and long emission fluorescence lifetime (Lai et al., 2016).

In this study, we applied GNP, QD, FNP, and EuNP as labels in a sandwich ICA system to quantitatively detect pathogens in milk. We selected E. coli O157:H7 as the target analyte. To our knowledge, direct comparisons of these 4 ICA labels to detect pathogens in milk have not yet been reported.

\section{MATERIALS AND METHODS}

\section{Materials and Instruments}

Carboxylic acid-modified CdSSe/ZnS QD (excitation wavelength $=365 \mathrm{~nm}$, emission wavelength $=610$ $\mathrm{nm}$ ) were purchased from Nanjing Technology Co., Ltd. (Hangzhou, China). Fluorescein isothiocyanate (FITC) FNP (excitation wavelength $=470 \mathrm{~nm}$, emission wavelength $=525 \mathrm{~nm}$ ) were purchased from Merck Co. (Darmstadt, Germany); EuNP (excitation wavelength $=365 \mathrm{~nm}$, emission wavelength $=615 \mathrm{~nm}$ ) were purchased from Weice Biotech Co. (Nanjing, China). Anti-E. coli O157:H7 monoclonal antibody (mAb) and rabbit anti-E. coli O157:H7 polyclonal antibody (pAb) were purchased from Meridian Life Science, Inc. (Memphis, TN). Nitrocellulose (NC) membrane, absorbent pad, sample pad, and conjugate pad were purchased from Millipore (Bedford, MA). Gold chloride trihydrate $\left(\mathrm{HAuCl}_{4} \cdot 3 \mathrm{H}_{2} \mathrm{O}, \quad 99.9 \%\right), \quad N$-(3-dimethylaminopropyl)$N^{\prime}$-ethylcarbodiimide hydrochloride (EDC·HCl), $N$-hydroxysulfosuccinimide (sulfo-NHS), and BSA from Sigma-Aldrich Chemical Co. (St. Louis, MO). We obtained glucosamine hydrochloride $\left(\mathrm{glu}-\mathbf{N H}_{2}\right)$ from Aladdin Chemistry Co. Ltd. (Shanghai, China). Milk was purchased from the Rainbow Supermarket in Nanchang, China. All other chemicals and reagents were of analytical grade and purchased from Sinopharm Chemical Reagent Co. Ltd. (Shanghai, China).

The 4 portable strip readers for the GNP-immunochromatographic test strip (ICTS, absorption wavelength $=525 \mathrm{~nm}$ ), QD-ICTS (excitation wavelength $=$ $365 \mathrm{~nm}$, emission wavelength $=610 \mathrm{~nm})$, FNP-ICTS (excitation wavelength $=470 \mathrm{~nm}$, emission wavelength $=540 \mathrm{~nm}$ ), and EuNP-ICTS (excitation wavelength $=365 \mathrm{~nm}$, emission wavelength $=610 \mathrm{~nm}$ ) were all obtained from Fenghang Scientific Instrument Co., Ltd. (Zhejiang, China). We used the delayed time-resolved mode of the EuNP-ICTS portable strip reader with a $200-\mu$ s delay time and a 400- $\mu$ s counting window. The
BioDot XYZ platform, equipped with a motion controller for solution dispensing, was supplied by BioDot (Irvine, CA).

\section{Bacterial Strains}

We used E. coli O157O157:H7 (ATCC 43888) and 14 non-E. coli O157O157:H7 strains: Listeria welshimeri (ATCC 35897), Listeria innocua (ATCC 33090), L. monocytogenes (ATCC 13932), Micrococcus luteus (CMCC 28001), Shigella sonnei (CMCC 51592), Shigella flexneri (CMCC 2457), Proteus vulgaris (CMCC 49027), Enterobacter sakazakii (CMCC 45407), Bacillus subtilis (BD 366), Bacillus cereus (ATCC 14579), Pseudomonas aeruginosa (CMCC 11997), Salmonella choleraesuis (CICC 21493), S. choleraesuis (ATCC 10708), and E. coli (CMCC 44102). All strains were preserved in our laboratory.

\section{Preparation of GNP}

The GNP were prepared according to a previously described citrate reduction method (Li et al., 2013). Gold chloride trihydrate solution $[100 \mathrm{~mL}, 0.01 \%$ (wt/ vol)] in ultra-pure water was heated to boiling. Then, $1.45 \mathrm{~mL}$ of $1 \%$ (wt/vol) sodium citrate solution was added under constant stirring. The solution was maintained at a boiling temperature for $5 \mathrm{~min}$ and then stored at $4^{\circ} \mathrm{C}$ for further use.

\section{Preparation of Labeled $m A b$}

To prepare the GNP-mAb, the $\mathrm{pH}$ of the colloidal gold solution was adjusted to 4.0, 5.0, 6.0, 7.0, and 8.0 with $0.1 \mathrm{M} \mathrm{HCl}$ or $0.2 \mathrm{M} \mathrm{K}_{2} \mathrm{CO}_{3}$. Then, anti- $E$. coli O157: $\mathrm{H} 7 \mathrm{mAb}\left(1.0,4.0,7.0\right.$, or $\left.10.0 \mu \mathrm{g} \mathrm{mL} \mathrm{m}^{-1}\right)$ were added dropwise to $1 \mathrm{~mL}$ of the GNP solution to form the GNP-mAb complex. The solution was agitated for $60 \mathrm{~min}$. Then, $100 \mu \mathrm{L}$ of blocking solution containing $10 \%$ (wt/vol) BSA was added to the mixture and agitated for 30 min. Finally, the resulting mixture was centrifuged at $6,948 \times g$ for $30 \mathrm{~min}$ at $4^{\circ} \mathrm{C}$. The precipitate was dissolved in $0.1 \mathrm{~mL}$ of PBS solution containing $5 \%$ sucrose, $2 \%$ trehalose, $1 \%$ polyethylene glycol 20,000, $1 \%$ BSA, and $0.25 \%$ Tween 20.

To prepare the QD-mAb, $10 \mu \mathrm{g}$ of $\mathrm{QD}$ was added to $200 \mu \mathrm{L}$ of $0.05 M$ borate buffer ( $\mathrm{pH} 4.0,5.0,6.0,7.0$, or 8.0) containing $1.25 \mu \mathrm{g}$ of EDC. $\mathrm{HCl}$ and $0.31 \mu \mathrm{g}$ of sulfo-NHS for 30 min to activate the carboxyl group of QD. Then, anti-E. coli $\mathrm{O} 157: \mathrm{H} 7 \mathrm{mAb}$ (23.1, 46.2, 69.3, or $92.4 \mu \mathrm{g} \mathrm{mL}^{-1}$ ) was added dropwise to the mixture to form the QD-mAb complex. The resulting mixture was agitated for $15 \mathrm{~min}$. Then, $35 \mu \mathrm{L}$ of blocking solution 
containing $1 \%$ (wt/vol) glu- $\mathrm{NH}_{2}$ was added, and the solution was agitated for $45 \mathrm{~min}$. Then, $75 \mu \mathrm{L}$ of $10 \%$ (wt/vol) glu- $\mathrm{NH}_{2}$ was added to the solution. Finally, the resulting mixture was centrifuged at $25,038 \times g$ for $10 \mathrm{~min}$ at $4^{\circ} \mathrm{C}$. The precipitate was dissolved in $200 \mu \mathrm{L}$ of $0.01 M$ PBS at pH 7.4 containing $20 \%$ glycerin (vol/ $\mathrm{vol})$.

To prepare the FNP-mAb, we used the EDC.HClmediated method as previously reported, with some modifications (Liu et al., 2015). The FNP $(50 \mu \mathrm{g})$ were added to $1 \mathrm{~mL}$ of $0.02 \mathrm{M}$ phosphate buffer ( $\mathrm{pH} 4.0,5.0$, $6.0,7.0$, or 8.0) containing $4.25 \mu \mathrm{g}$ of $\mathrm{EDC} \cdot \mathrm{HCl}$ to activate the carboxyl groups of FNP. Anti- $E$. coli O157:H7 $\mathrm{mAb}\left(0.4,0.7,1.0\right.$, or $\left.3.0 \mu \mathrm{g} \mathrm{mL}^{-1}\right)$ was added dropwise to the mixture to form the FNP-mAb complex. The solution was agitated for $2 \mathrm{~h}$. Then, the FNP-mAb solution was blocked with $100 \mu \mathrm{L}$ of blocking solution containing $10 \%$ (wt/vol) BSA. Finally, the mixture was separated by centrifugation at $10,005 \times g$ for $10 \mathrm{~min}$ at $4^{\circ} \mathrm{C}$. The precipitate was dissolved in $100 \mu \mathrm{L}$ of 0.02 $M \mathrm{Na}_{2} \mathrm{HPO}_{4}$ containing $1 \% \mathrm{BSA}$ (wt/vol), 5\% sucrose (wt/vol), 3\% trehalose (wt/vol), 1\% Tween 20 (vol/ vol), and $0.1 \% \mathrm{NaN}_{3}$ (wt/vol) at $\mathrm{pH} 7.4$.

To prepare EuNP-mAb, $50 \mu \mathrm{g}$ of EuNP were added to $500 \mu \mathrm{L}$ of $0.05 M$ borate buffer ( $\mathrm{pH} 4.0,5.0,6.0,7.0$, or 8.0) containing $1.75 \mu \mathrm{g}$ of EDC. $\mathrm{HCl}$ to activate the carboxyl of EuNP. Anti-E. coli O157:H7 mAb (5, 10, 15 , or $20 \mu \mathrm{g} \mathrm{mL} \mathrm{m}^{-1}$ ) was added dropwise to the mixture to form the EuNP-mAb complex. The solution was agitated for $2 \mathrm{~h}$. Then, the EuNP-mAb solution was blocked with $50 \mu \mathrm{L}$ of $0.05 \mathrm{M}$ borate buffer containing $10 \%$ (wt/vol) BSA and 1\% (vol/vol) Tween 20 at $\mathrm{pH}$ 7.0. Finally, the mixture was centrifuged at 17,788 $\times g$ for $20 \mathrm{~min}$ at $4^{\circ} \mathrm{C}$. The precipitate was dissolved at $\mathrm{pH} 7.0$ in $100 \mu \mathrm{L}$ of $0.05 \mathrm{M}$ borate buffer containing $0.2 \%$ (wt/vol) BSA and 0.5\% (vol/vol) Tween 20 .

\section{Characterization of Labels and Label-mAb Complex}

The morphology and size of the 4 labels (GNP, QD, FNP, and EuNP) were analyzed by transmission electron microscope (JEM 2100; Jeol, Tokyo, Japan) and a scanning electron microscope (S-4800; Hitachi, Tokyo, Japan). The UV-visible absorption spectra of GNP were recorded using a UV-visible spectrophotometer (Genesys 10S, Thermo Scientific, Waltham, MA). The fluorescence spectra of QD, FNP, and EuNP were recorded using a fluorescence spectrophotometer (F380; Guangdong Scientific Ltd., Tianjin, China). The dynamic light scattering of the 4 labels and the label-mAb complexes was analyzed using a particle size analyzer (Nano-ZS; Malvern Instruments Ltd., Malvern, UK).

\section{Preparation of ICTS}

The ICTS consisted of a sample pad, a conjugate pad, a nitrocellulose membrane, and an absorbent pad (Figure 1). The sample pads were pretreated with 20 $\mathrm{m} M$ sodium borate buffer [( $\mathrm{pH} 8.0)$ containing $1.0 \%$ (wt/vol) BSA, $0.05 \%$ (wt/vol) $\mathrm{NaN}_{3}$, and $0.5 \%$ Tween 20] and then dried at $60^{\circ} \mathrm{C}$ for $2 \mathrm{~h}$. The pAb to $E$. coli O157:H7 and goat anti-mouse IgG were sprayed on the nitrocellulose membrane as test and control lines, respectively, and the membranes were dried at $37^{\circ} \mathrm{C}$ for $16 \mathrm{~h}$. The sample pad, conjugate pad, nitrocellulose membrane, and absorbent pad were assembled, cut into strips $4 \mathrm{~mm}$ wide, and packaged in foil bags.

\section{Detection of 4 ICA}

The label-mAb complexes were premixed with 100 $\mu \mathrm{L}$ of sample in ELISA microplate wells for $5 \mathrm{~min}$, and then the mixture was added to the sample pad of the ICTS (Figure 1). After a period of reaction, the absorbance of the test line $\left(\mathbf{A}_{\mathbf{T}}\right)$ was recorded by the GNP-ICTS portable strip reader to quantitatively determine E. coli $\mathrm{O} 157: \mathrm{H} 7$, and the fluorescent intensity of the test line $\left(\mathbf{F I}_{\mathbf{T}}\right)$ was recorded by the QD-ICTS, FNP-ICTS, and EuNP-ICTS portable strip readers to quantitatively determine E. coli $\mathrm{O} 157: \mathrm{H} 7$. The emission fluorescence signal of the EuNP-ICA was recorded after a $200-\mu$ s delay and a $400-\mu$ s counting window.

\section{Immunological Kinetics Analysis of 4 ICA}

The immunological kinetics of GNP-ICA, QD-ICA, FNP-ICA, and EuNP-ICA were studied for 30, 60, 40, and $30 \mathrm{~min}$, respectively. The signal intensity of the test line was recorded every $30 \mathrm{~s}$. The concentration of

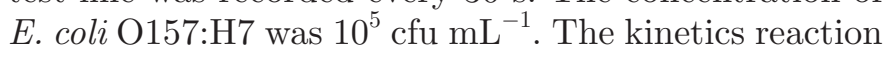
curve was established by plotting the signal intensity of the test line against the immunoreaction time.

\section{Standard Calibration Curve of 4 ICA}

The standard calibration curve was established by plotting the logarithm of $\mathrm{A}_{\mathrm{T}}$ or $\mathrm{FI}_{\mathrm{T}}$ against the logarithm of the $E$. coli O157:H7 concentration. Different E. coli O157:H7 concentrations $\left(0,1.0 \times 10^{2}, 2.5 \times\right.$ $10^{2}, 5.0 \times 10^{2}, 1.0 \times 10^{3}, 2.5 \times 10^{3}, 5.0 \times 10^{3}, 1.0 \times$ $10^{4}, 2.5 \times 10^{4}, 5.0 \times 10^{4}, 1.0 \times 10^{5}, 2.5 \times 10^{5}, 5.0 \times$ $10^{5}$, and $1.0 \times 10^{6} \mathrm{cfu} \mathrm{mL}^{-1}$ ) were prepared by diluting $10^{8} \mathrm{cfu} \mathrm{mL}^{-1}$ of E. coli $\mathrm{O} 157: \mathrm{H} 7$ with $0.01 M$ PBS (pH 7.4). Sensitivity was defined as the mean plus 3 -fold 
standard deviation (SD) of the negative sample (Oh et al., 2009).

\section{Specificity of 4 ICA}

The specificity of the 4 ICA was estimated by testing 15 bacterial strains, including the E. coli O157:H7 $\left(10^{6}\right.$ cfu $\mathrm{mL}^{-1}$ ) target strain and 14 non- $E$. coli $\mathrm{O} 157: \mathrm{H} 7$ strains $\left(10^{6} \mathrm{cfu} \mathrm{mL}^{-1}\right)$. A negative test was performed with sterile PBS solution. The experiment was repeated in triplicate.

\section{Analysis of Milk Sample}

We added $0.1 \mathrm{~mL}$ of E. coli $\mathrm{O} 157: \mathrm{H} 7$ to $1 \mathrm{~mL}$ of milk $\left(1.0 \times 10^{4}, 2.5 \times 10^{4}, 5.0 \times 10^{4}, 1.0 \times 10^{5}\right.$, and $2.5 \times 10^{5}$ cfu per $\mathrm{mL}$ of milk). The spiked milk was then homogenized for $1 \mathrm{~min}$. The accuracy and precision of the 4 ICA were evaluated by analyzing recovery and coefficient of variation $(\mathbf{C V})$. The experiment was repeated in triplicate. Milk samples spiked with $E$. coli O157:H7 at a concentration of $5.0 \times 10^{4}, 1.0 \times 10^{5}$, or $2.5 \times 10^{5} \mathrm{cfu} \mathrm{mL}^{-1}$ were quantitatively analyzed using

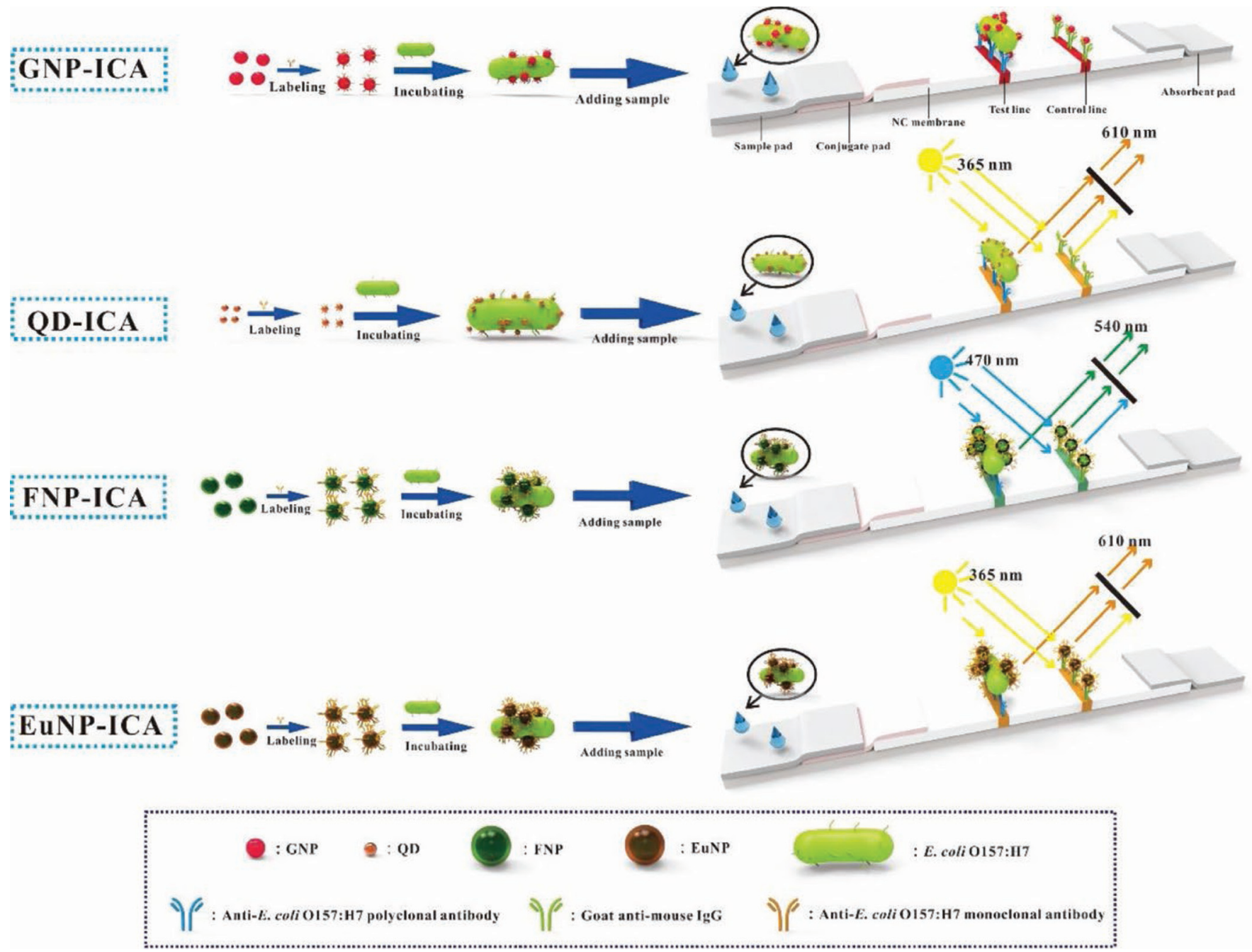

Figure 1. Schematic illustration of the 4 label-based immunochromatographic assays (ICA) used to quantitatively analyze Escherichia coli O157:H7. When the target $E$. coli $\mathrm{O} 157: \mathrm{H} 7$ was included in the sample, the label-monoclonal antibody (mAb) bound with $E$. coli O157:H7 to form the label-mAb-E. coli O157:H7 immunocomplex, which then migrated across the nitrocellulose (NC) membrane. The immunocomplex was then captured by polyclonal antibody (pAb) and goat anti-mouse IgG to form signals on both test and control lines. When E. coli O157:H7 was excluded from the sample, the label-mAb could not be captured by the pAb to form the sandwich immunocomplex, resulting in an absence of the test line signal. GNP = gold nanoparticle; QD = quantum dot; FNP = fluorescent nanoparticle; EuNP = europium (III) chelate nanoparticle. Color version available online. 
the GNP-ICA and QD-ICA. Milk samples spiked with E. coli $\mathrm{O} 157: \mathrm{H} 7$ at a concentration of $1.0 \times 10^{4}, 2.5 \times$ $10^{4}$, or $5.0 \times 10^{4} \mathrm{cfu} \mathrm{mL}^{-1}$ were quantitatively analyzed using the FNP-ICA and EuNP-ICA.

Different E. coli O157:H7 concentrations $(0,1.0 \times$ $10^{2}, 2.5 \times 10^{2}, 5.0 \times 10^{2}, 1.0 \times 10^{3}, 2.5 \times 10^{3}, 5.0 \times$ $10^{3}, 1.0 \times 10^{4}, 2.5 \times 10^{4}, 5.0 \times 10^{4}, 1.0 \times 10^{5}, 2.5 \times 10^{5}$, $5.0 \times 10^{5}$, and $1.0 \times 10^{6} \mathrm{cfu} \mathrm{mL}^{-1}$ ) were prepared by diluting $10^{8} \mathrm{cfu} \mathrm{mL}^{-1}$ of E. coli $\mathrm{O} 157: \mathrm{H} 7$ in sterile PBS solution or milk. The spiked samples were then homogenized for $1 \mathrm{~min}$. The standard calibration curves of the 4 ICA of sterile PBS solution and milk samples were established by plotting the logarithm of $\mathrm{A}_{\mathrm{T}}$ or $\mathrm{FI}_{\mathrm{T}}$ against the logarithm of E. coli O157:H7 concentration. The matrix effect of milk on the sensitivity of the 4 ICA was identified by comparing the differences between the standard calibration curves in sterile PBS solution and milk.

\section{RESULTS AND DISCUSSION}

\section{Characterization of Free Labels and Label-mAb Complexes}

We characterized the morphology and size of the 4 labels (GNP, QD, FNP, and EuNP) using a transmission electron microscope (Figures 2A to D) and a scanning electron microscope (Figures 2E to $\mathrm{H}$ ). The transmission and scanning electron micrographs showed that GNP, QD, FNP, and EuNP were relatively
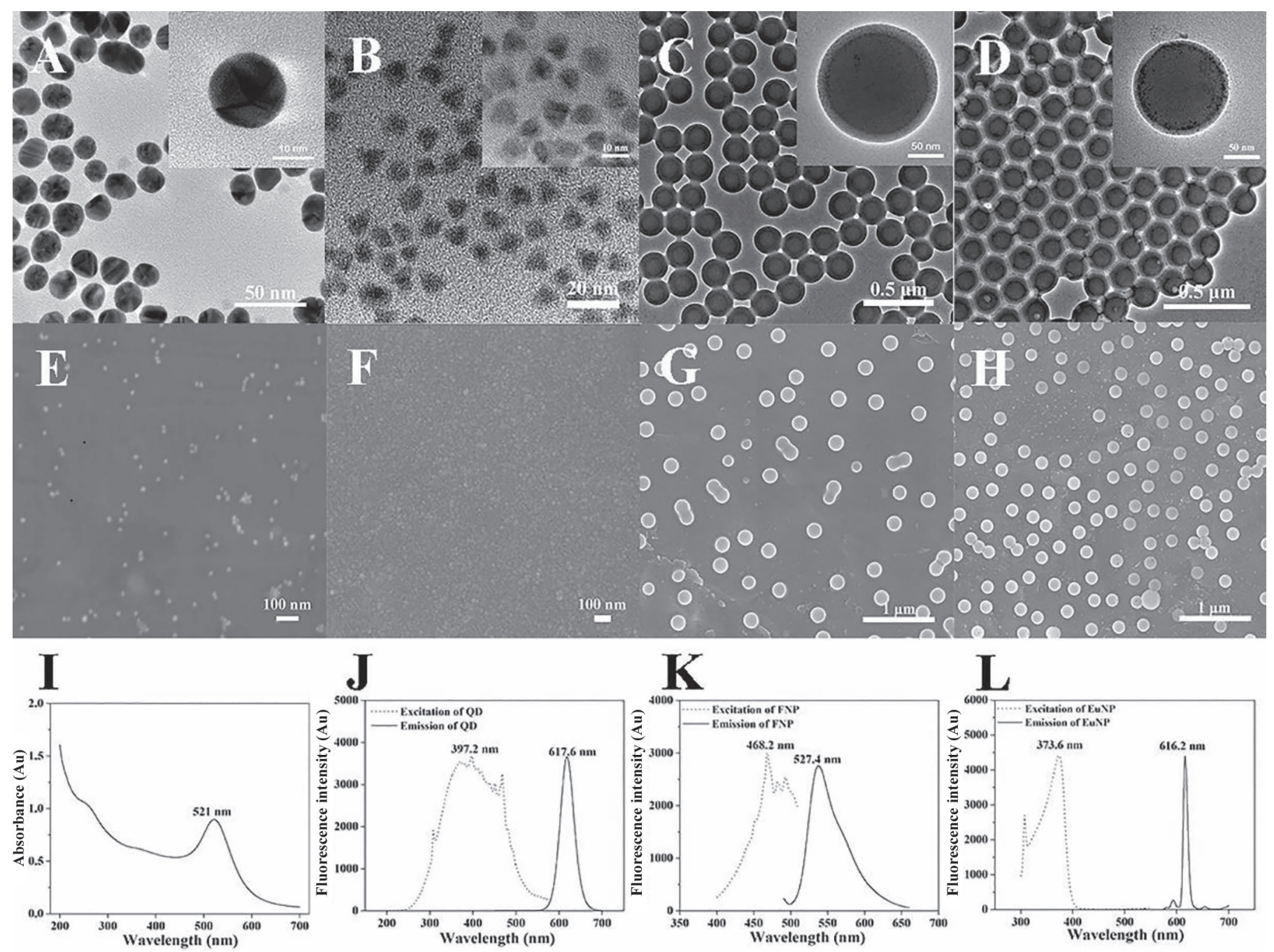

Figure 2. Characterization of the 4 labels. Transmission electron micrographs of (A) gold nanoparticle (GNP); (B) quantum dot (QD); (C) fluorescent nanoparticle (FNP); and (D) europium (III) chelate nanoparticle (EuNP). Scanning electron micrographs of (E) GNP; (F) QD; (G) FNP; and (H) EuNP. The UV-visible absorption spectrum of (I) GNP and the fluorescence spectra of (J) QD; (K) FNP; and (L) EuNP. 
uniform in size and had average diameters of 21, 11 , 182, and $155 \mathrm{~nm}$, respectively. Figures $2 \mathrm{C}$ and D (inset) illustrated that numerous fluorescein isothiocyanate molecules and $\mathrm{Eu}$ (III) chelates were tightly embedded in the polystyrene matrices of FNP and EuNP. Figure 2I showed that the UV-visible absorption spectrum of GNP exhibited a maximum surface plasmon resonance absorption at $521 \mathrm{~nm}$ at concentrations of $0.5 \mathrm{mg}$ $\mathrm{mL}^{-1}$. Fluorescence spectra showed that the maximum excitation wavelength $\left(\boldsymbol{\lambda}_{\mathrm{ex}}\right)$ and maximum emission wavelength $\left(\boldsymbol{\lambda}_{\mathrm{em}}\right)$ of QD, FNP, and EuNP (Figure 2 $\mathrm{J}$ to $\mathrm{L}$ ) were 397.2 and $617.6,468.2$ and 527.4, and 373.6 and $616.2 \mathrm{~nm}$, respectively, at concentration of $0.5 \mathrm{mg} \mathrm{mL}{ }^{-1}$. The maximum emission fluorescence intensities were 3,655, 2,115, and 4,397 for QD, FNP, and EuNP, respectively. The EuNP had the highest fluorescence intensity. This characteristic contributed remarkably to improvements in the sensitivity of the ICA. Furthermore, the Stokes shifts of QD, FNP, and EuNP were 220.4, 59.2, and 242.6, respectively, and the corresponding emission profiles with the full width at half-maximum were 37.8, 63.9, and $10 \mathrm{~nm}$. The EuNP showed the largest Stokes shift and sharpest emission profile, facilitating discrimination against light scattering background autofluorescence associated with QD and FNP (Zhang et al., 2014b). Finally, EuNP had the longest emission fluorescence lifetime (1 ms) compared with QD (12 to 28 ns; Labeau et al., 2003) and FNP
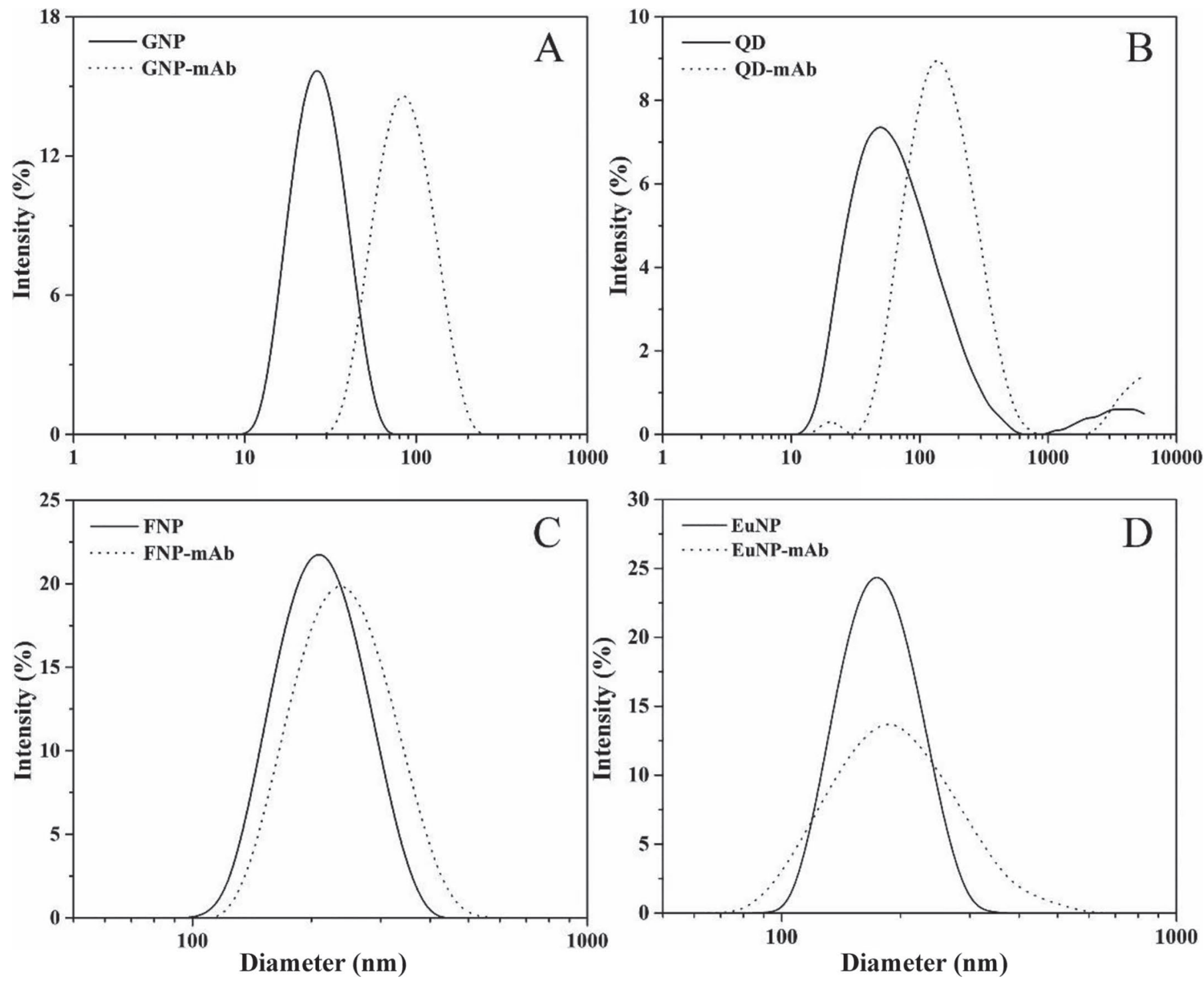

Figure 3. Hydrodynamic diameters of (A) gold nanoparticle (GNP) and GNP-monoclonal antibody (mAb) (GNP-mAb); (B) quantum dot (QD) and QD-mAb; (C) fluorescent nanoparticle (FNP) and FNP-mAb; and (D) europium (III) chelate nanoparticle (EuNP) and EuNP-mAb. 
$(<10$ ns; Santra et al., 2006). This characteristic could also eliminate background autofluorescence, resulting in higher sensitivity (Yang et al., 2016).

We formed the GNP-mAb by electrostatic adsorption between GNP and mAb, but synthesized the QD-mAb, FNP-mAb, and EuNP-mAb by coupling the carboxyl group of the labels with the amino group of the $\mathrm{mAb}$ using the EDC.HCl-mediated method. We compared the dynamic light scattering results of the 4 labels and label-mAb complexes to confirm that the mAb were coupled on the surface of the labels. Figure 3 shows that the hydrodynamic diameters of GNP, QD, FNP, and EuNP were $23 \pm 0.1,55 \pm 1.1,206 \pm 1.3$, and 178 $\pm 4.2 \mathrm{~nm}$, respectively. The hydrodynamic diameters of GNP-mAb, QD-mAb, FNP-mAb, and EuNP-mAb were $76 \pm 1.8,133 \pm 1.3,227 \pm 3.1$, and $190 \pm 1.9$ $\mathrm{nm}$, respectively. These results indicated that the $\mathrm{mAb}$ were successfully coupled on the surface of the 4 labels. Additionally, we studied the polydispersity index (PDI) to analyze the size distribution of the 4 labels and label-mAb complexes (Figure 4). The PDI of GNP, $\mathrm{QD}, \mathrm{FNP}$, and EuNP were $0.24 \pm 0.01,0.35 \pm 0.04$, $0.06 \pm 0.01$, and $0.04 \pm 0.01 \mathrm{~nm}$, respectively. The PDI of GNP-mAb, QD-mAb, FNP-mAb, and EuNP$\mathrm{mAb}$ increased to $0.26 \pm 0.01,0.36 \pm 0.01,0.11 \pm$ 0.03 , and $0.10 \pm 0.03 \mathrm{~nm}$, respectively. A lower PDI indicated better size distribution and resulted in better sensitivity to the ICA (Cui et al., 2015). The EuNP and EuNP-mAb showed the lowest PDI, which created better conditions for the application of the label in the ICA.

\section{Optimization of ICA}

We labeled the 4 ICA under different $\mathrm{pH}$ values (4.0, $5.0,6.0,7.0$, and 8.0) and analyzed them by studying the signal intensities of their test lines. We prepared sterile PBS solution without E. coli O157:H7 (negative sample) and sterile PBS solution spiked with $10^{5} \mathrm{cfu}$ $\mathrm{mL}^{-1}$ of E. coli O157:H7 (positive sample). For GNPICA, when the label $\mathrm{pH}$ was adjusted to 4.0, 5.0, 6.0, 7.0, and 8.0, the $\mathrm{A}_{\mathrm{T}}$ of the positive sample were $544 \pm$ $10,984 \pm 91,1,224 \pm 217,317 \pm 22$, and $218 \pm 48$, respectively (Supplemental Figure S1A; https://doi. org/10.3168/jds.2017-12554). We determined that the optimal pH for GNP-ICA was 6.0 because of the strong $\mathrm{A}_{\mathrm{T}}$ of the positive sample and the low $\mathrm{A}_{\mathrm{T}}$ of the negative sample. As labeling $\mathrm{pH}$ increased, the $-\mathrm{COOH}$ groups on the surfaces of the carboxylic acid-modified photoluminescent label-based ICA (QD-ICA, FNP-ICA, and EuNP-ICA) gradually transformed into $-\mathrm{COO}^{-}$. The optimal labeling $\mathrm{pH}$ values for QD-ICA, FNP-ICA, and EuNP-ICA were $\mathrm{pH}$ 6.0, 5.0, and 6.0, respectively, because of the strong $\mathrm{FI}_{\mathrm{T}}$ of the positive sample and the low $\mathrm{FI}_{\mathrm{T}}$ of the negative sample (Supplemental Figure S1B-D).

We also investigated the effect of the amount of $\mathrm{mAb}$ on the signal intensity of the proposed assay. We analyzed the 4 ICA labeled with different amounts of $\mathrm{mAb}$ by studying the signal intensities of their test lines. We prepared sterile PBS solution without E. coli O157:H7 (negative sample) and sterile PBS solution spiked with $10^{6} \mathrm{cfu} \mathrm{mL}^{-1}$ of E. coli O157:H7 (positive sample). The optimal labeling amounts of $\mathrm{mAb}$ for GNP-ICA, QDICA, FNP-ICA, and EuNP-ICA were 4.0, 46.2, 1.0, and $10.0 \mu \mathrm{g} \mathrm{mL}^{-1}$, respectively, because of the strong $\mathrm{A}_{\mathrm{T}}$ or $\mathrm{FI}_{\mathrm{T}}$ of the positive sample and the weak $\mathrm{A}_{\mathrm{T}}$ or $\mathrm{FI}_{\mathrm{T}}$ of the negative sample (Supplemental Figure S2; https:// doi.org/10.3168/jds.2017-12554).

We investigated the immunological kinetics of the 4 ICA by recording $A_{T}$ or $\mathrm{FI}_{T}$ every $30 \mathrm{~s}$. Supplemental Figure S3 (https://doi.org/10.3168/jds.2017-12554) illustrates that $\mathrm{A}_{\mathrm{T}}$ of GNP-ICA remained stable after 20 min, and the $\mathrm{FI}_{\mathrm{T}}$ of QD-ICA, FNP-ICA, and EuNP-ICA remained stable after 50,30, and 25 min, respectively.

\section{Analytical Performance of ICA}

We constructed the calibration curve of the 4 labelbased ICA under optimal experimental conditions by plotting the logarithm of $\mathrm{A}_{\mathrm{T}}$ or $\mathrm{FI}_{\mathrm{T}}$ against the logarithm of E. coli O157:H7 concentration. We then fitted the data using linear equations. The regression equations were $\log (\mathrm{Y})=0.7197 \log (\mathrm{X})-0.9694, \log (\mathrm{Y})$

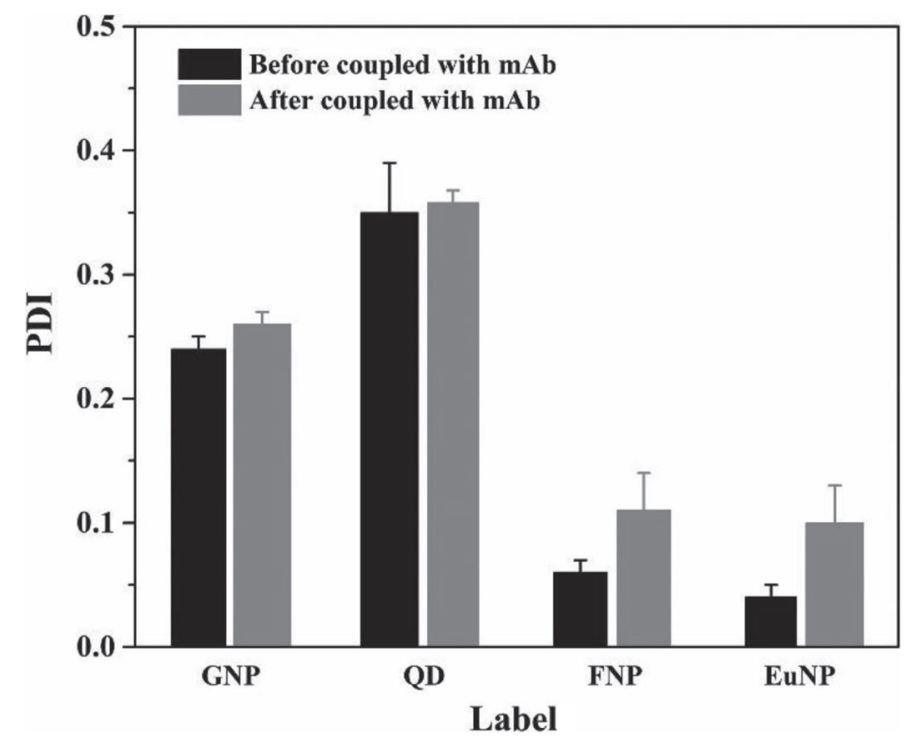

Figure 4. Polydispersity index (PDI) of the 4 labels before and after coupling with monoclonal antibodies $(\mathrm{mAb}) . \mathrm{EuNP}=$ europium (III) chelate nanoparticle; FNP = fluorescent nanoparticle; GNP = gold nanoparticle; QD = quantum dot. Vertical bars indicate the SD $(\mathrm{n}=3)$. 
Table 1. Comparison of the immunochromatographic assays (ICA) ${ }^{1}$

\begin{tabular}{lccc}
\hline ICA & $\begin{array}{c}\text { Sensitivity } \\
\left(\mathrm{cfu} \cdot \mathrm{mL}^{-1}\right)\end{array}$ & $\begin{array}{c}\text { Linear range } \\
\left(\mathrm{cfu} \cdot \mathrm{mL}^{-1}\right)\end{array}$ & $\begin{array}{c}\text { Amount of } \\
\mathrm{mAb}(\mu \mathrm{g})^{2}\end{array}$ \\
\hline GNP-ICA & $2.5 \times 10^{4}$ & $1.0 \times 10^{4}-1.0 \times 10^{6}$ & 0.16 \\
QD-ICA & $5.0 \times 10^{3}$ & $2.5 \times 10^{3}-1.0 \times 10^{6}$ & 0.37 \\
FNP-ICA & $1.0 \times 10^{3}$ & $2.5 \times 10^{2}-2.5 \times 10^{5}$ & 0.04 \\
EuNP-ICA & $5.0 \times 10^{2}$ & $2.5 \times 10^{2}-2.5 \times 10^{5}$ & 0.10 \\
\hline
\end{tabular}

${ }^{1} \mathrm{GNP}=$ gold nanoparticle; $\mathrm{QD}=$ quantum dot; FNP $=$ fluorescent nanoparticle; EuNP = europium (III) chelate nanoparticle.

${ }^{2}$ Per test strip.
$=0.6549 \log (\mathrm{X})-0.0017, \log (\mathrm{Y})=0.8154 \log (\mathrm{X})$ -0.6419 , and $\log (\mathrm{Y})=0.8127 \log (\mathrm{X})+0.2821$, with the reliable correlation coefficients $\mathrm{R}^{2}$ of $0.9653,0.9743$, 0.9897, and 0.9897 for GNP-ICA, QD-ICA, FNP-ICA, and EuNP-ICA, respectively (Figure 5).

We also compared the sensitivity and linear ranges of the 4 ICA (Table 1). The calculated sensitivities were $2.5 \times 10^{4}, 5.0 \times 10^{3}, 1.0 \times 10^{3}$, and $5.0 \times 10^{2} \mathrm{cfu} \mathrm{mL}^{-1}$ for the GNP-ICA, QD-ICA, FNP-ICA, and EuNPICA, respectively. These results indicated that the EuNP-ICA possessed the highest sensitivity compared with the GNP-ICA, QD-ICA, and FNP-ICA. This was due to the unique photoluminescent properties of lanthanide chelates, including high emission fluorescence

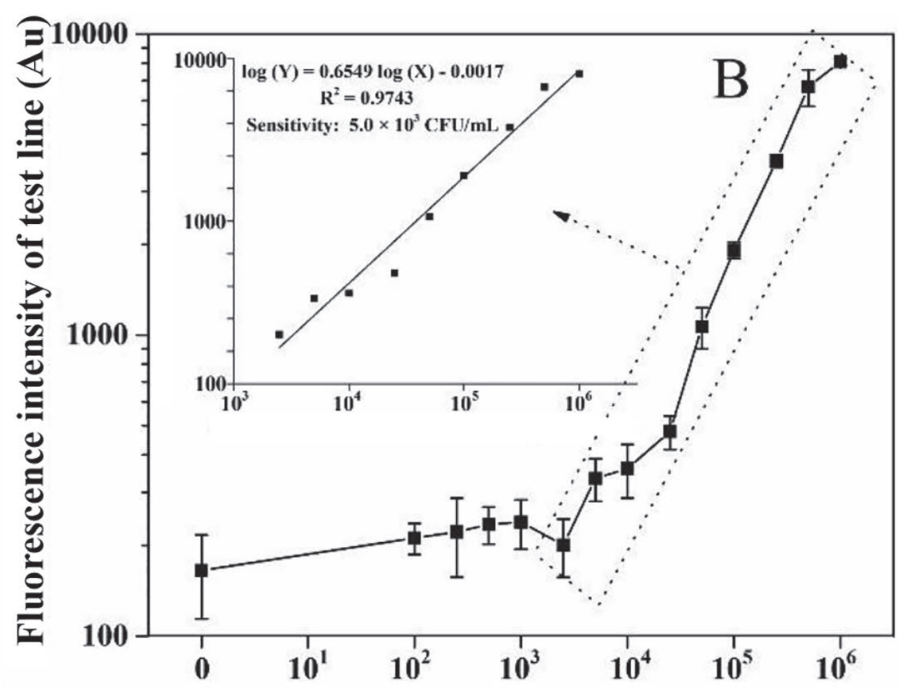

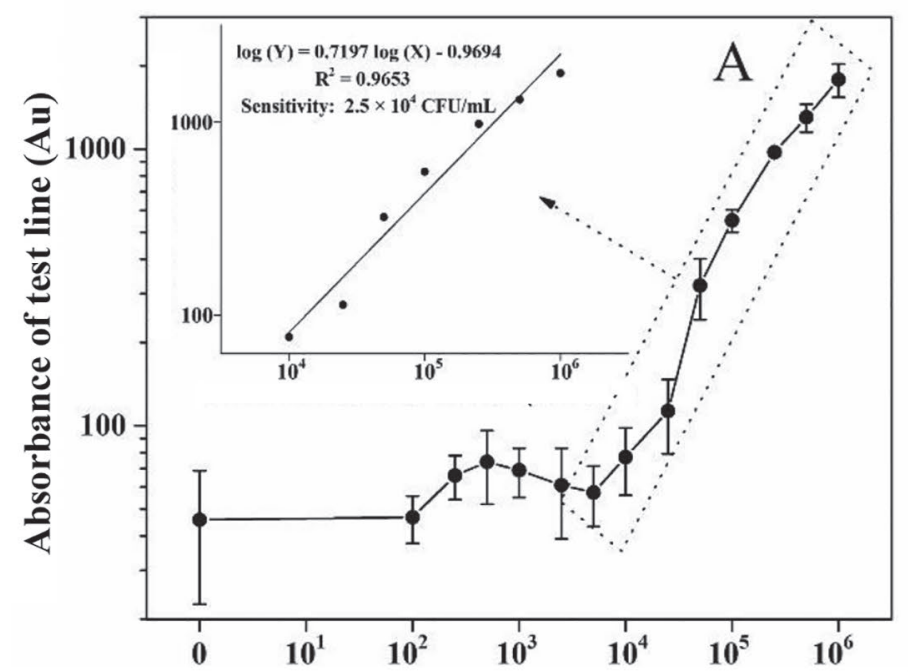

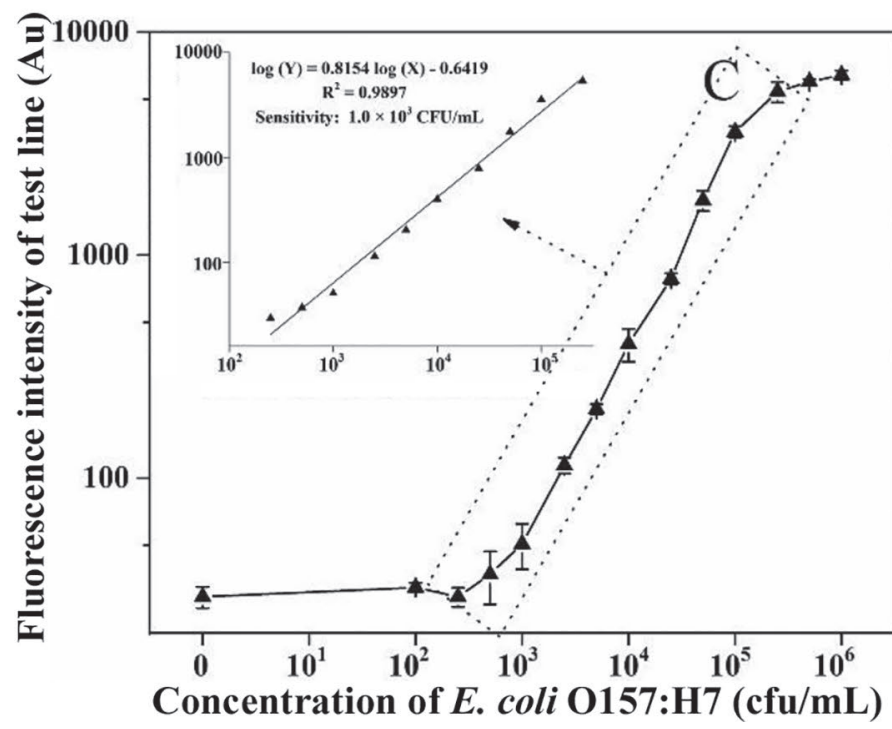

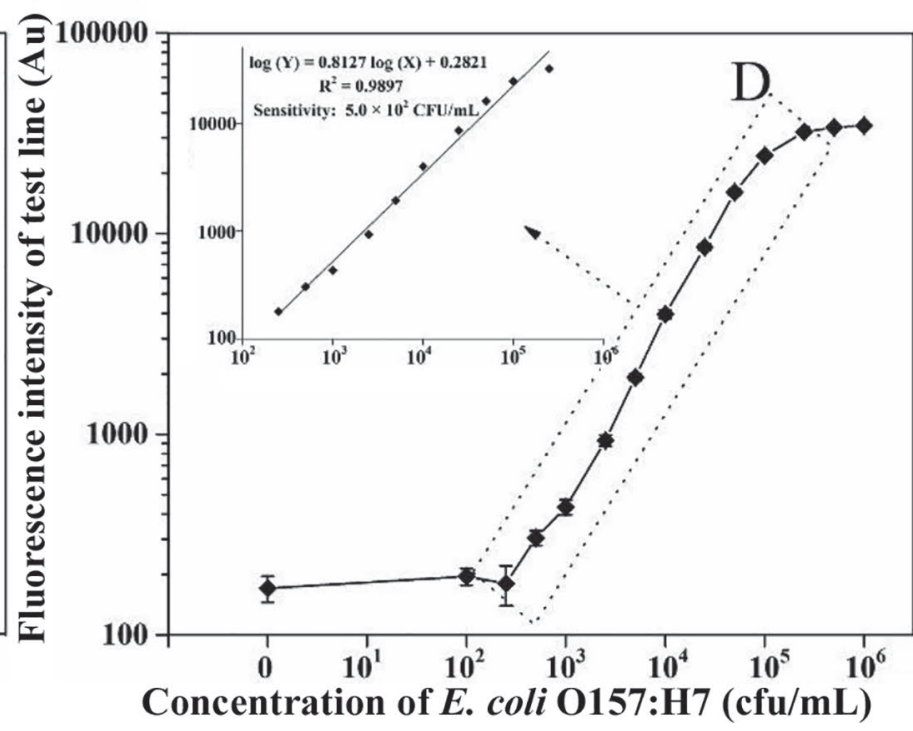

Figure 5. Calibration curves to quantitatively analyze Escherichia coli O157:H7. (A) Gold nanoparticle-based immunochromatographic assay (GNP-ICA); (B) quantum dot-based ICA (QD-ICA); (C) fluorescent nanoparticle-based ICA (FNP-ICA); and (D) europium (III) chelate nanoparticle-based ICA (EuNP-ICA). Sensitivity was defined as the mean plus 3-fold SD of the negative sample. Vertical bars indicate SD (n $=3)$. 
intensity, large Stokes shift, sharp emission profile, and long emission fluorescence lifetime (1 ms). Additionally, the delayed time-resolved mode of the EuNP-ICTS portable strip reader eliminated the background autofluorescence noise and achieved a high signal-to-noise
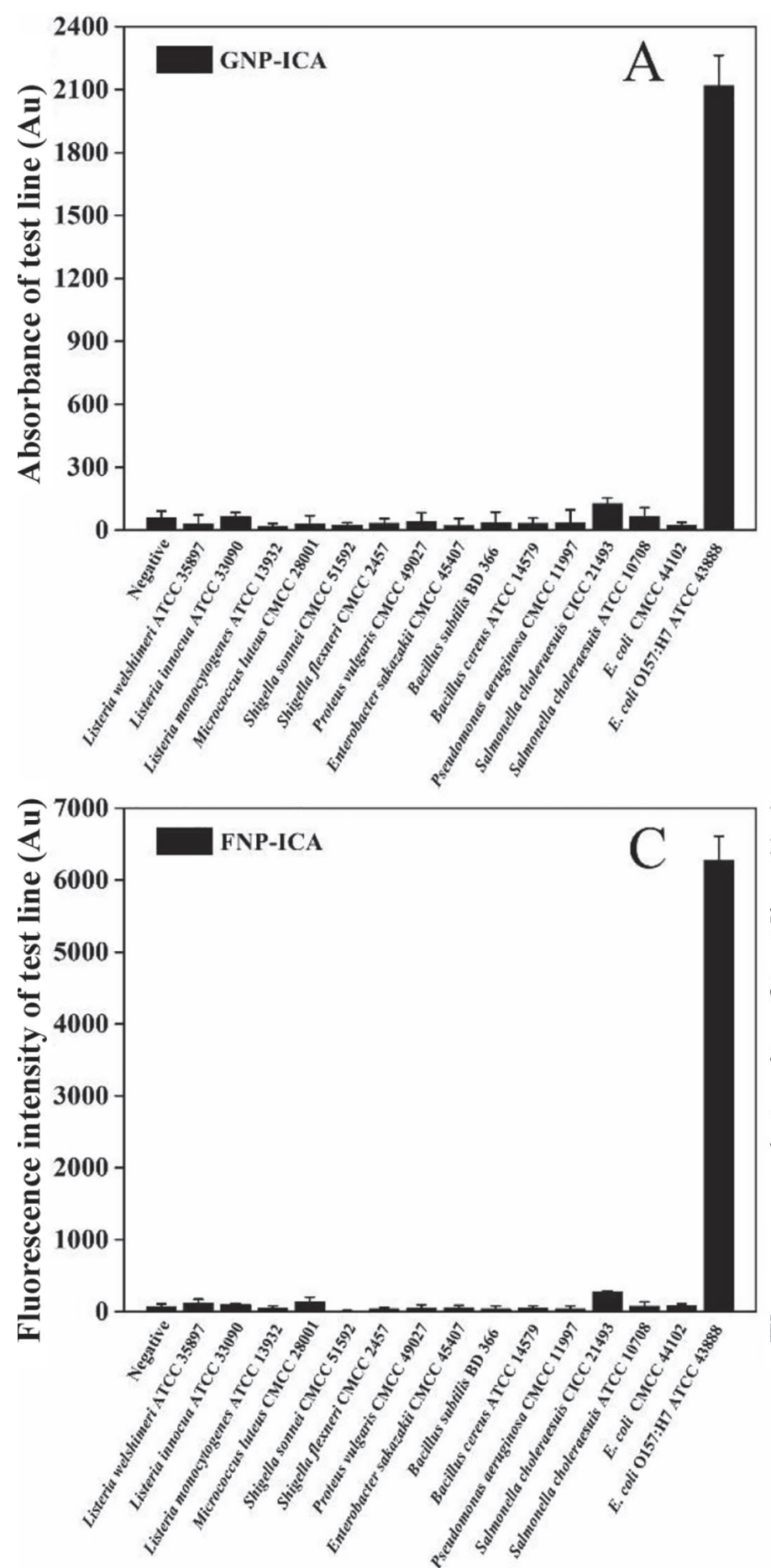

ratio. Moreover, the low PDI of the EuNP increased sensitivity. We also studied the linear ranges of the 4 ICA and found that the ranges of the FNP-ICA and the EuNP-ICA $\left(2.5 \times 10^{2}\right.$ to $\left.2.5 \times 10^{5} \mathrm{cfu} \mathrm{mL}^{-1}\right)$ were broader than those of the GNP-ICA $\left(1.0 \times 10^{4}\right.$ to 1.0
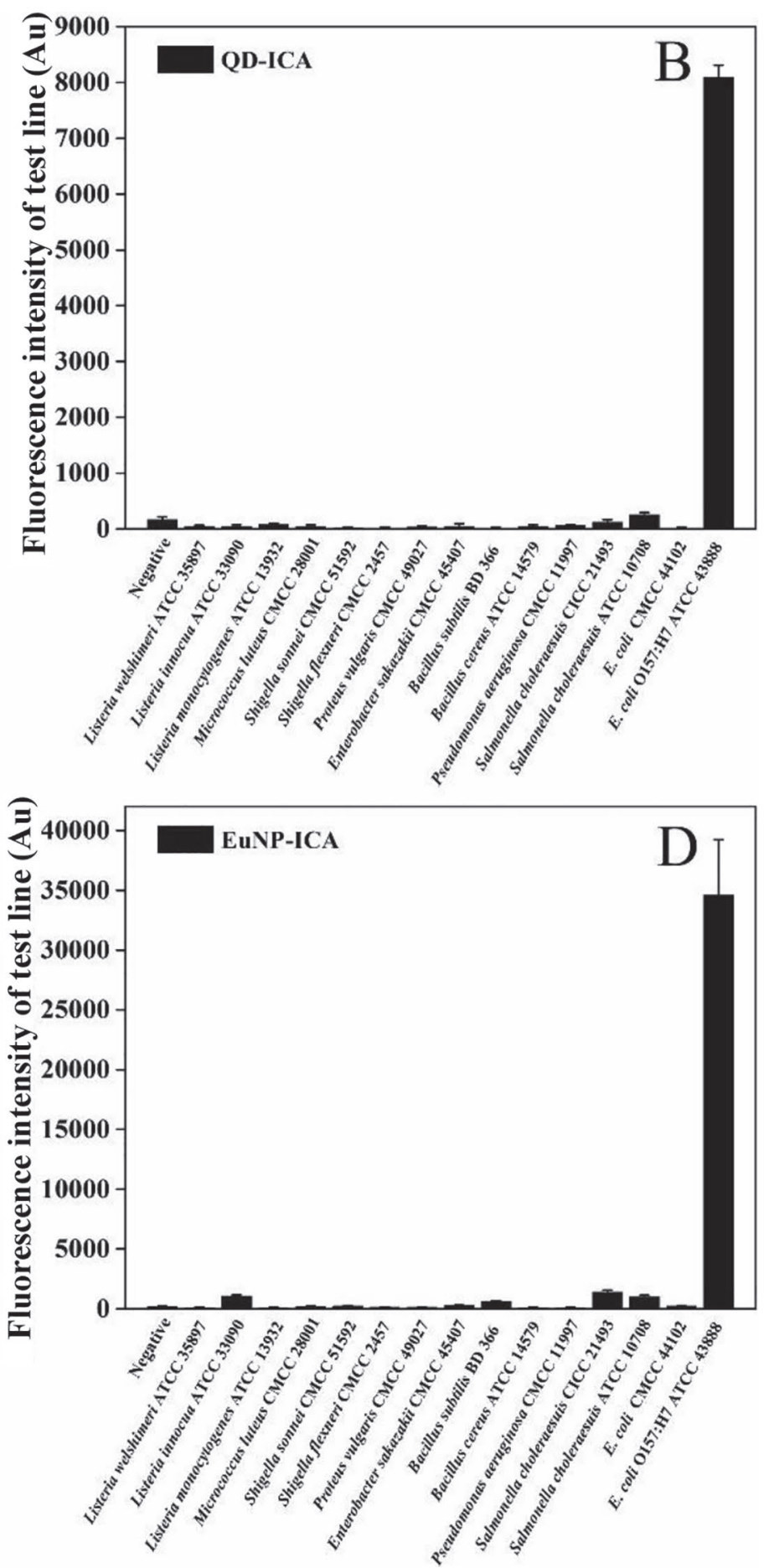

Figure 6. Specificity of the proposed 4 immunochromatographic assays (ICA) over other non-Escherichia coli O157:H7. EuNP-ICA = europium (III) chelate nanoparticle-based ICA; FNP-ICA = fluorescent nanoparticle-based ICA; GNP-ICA = gold nanoparticle-based ICA; QD-ICA $=$ quantum dot-based ICA. Vertical bars indicate $\mathrm{SD}(\mathrm{n}=3)$. 
$\left.\times 10^{6} \mathrm{cfu} \mathrm{mL}^{-1}\right)$ and the QD-ICA $\left(2.5 \times 10^{3}\right.$ to $1.0 \times$ $10^{6} \mathrm{cfu} \mathrm{mL}^{-1}$ ).

We calculated the amount of mAb per test strip to compare the amount of $\mathrm{mAb}$ of the 4 ICA (Table 1). The amounts of mAb per GNP-ICA, QD-ICA, FNPICA, and EuNP-ICA test strip were 0.16, 0.37, 0.04, and $0.10 \mu \mathrm{g}$, respectively. The FNP-ICA required the least amount of $\mathrm{mAb}$, presumably because the amount of $\mathrm{mAb}$ was inversely proportional to the surface area of the label. The FNP had the largest size, resulting in the largest surface area and least amount of $\mathrm{mAb}$ per test strip.

\section{Specificity of ICA}

We tested 15 bacterial strains to estimate the specificity of the 4 proposed ICA. The strains included E. coli O157:H7 (10 $\left.\mathrm{cfu} \mathrm{mL}^{-1}\right)$ and 14 non-E. coli $\mathrm{O} 157: \mathrm{H} 7$ strains $\left(10^{6} \mathrm{cfu} \mathrm{mL}^{-1}\right)$. We also performed a negative test using sterile PBS solution (Figure 6 ). The $\mathrm{A}_{\mathrm{T}}$ or $\mathrm{FI}_{\mathrm{T}}$ of ICA with the E. coli O157:H7 sample exhibited a strong signal, and the $\mathrm{A}_{\mathrm{T}}$ or $\mathrm{FI}_{\mathrm{T}}$ of the ICA with non- $E$. coli O157:H7 sample exhibited a weak signal. These results clearly demonstrated the high specificity of the 4 ICA to detect E. coli O157:H7.

\section{Accuracy and Precision of ICA}

We performed recovery experiments to evaluate the accuracy and precision of the 4 ICA using milk samples spiked with E. coli O157:H7. Table 2 shows that the recoveries of the 4 ICA ranged from 83.3 to $125.3 \%$, with $\mathrm{CV}$ in the range of 2.7 to $18.6 \%$. The proposed 4 ICA satisfied the requirements for the quantitative detection of E. coli $\mathrm{O} 157: \mathrm{H} 7$ in milk. The $\mathrm{CV}$ for the FNP-ICA was 2.7 to $7.8 \%$, better than those of for the
GNP-ICA (7.4 to $15.8 \%$ ), QD-ICA (10.4 to $18.6 \%$ ), and EuNP-ICA (6.9 to $10.5 \%)$.

\section{Tolerance of ICA in Milk Sample}

We investigated the influence of the milk sample on the sensitivity of the 4 ICA (Figure 7). The respective sensitivities of the 4 ICA in the spiked PBS and milk were as follows: GNP-ICA, $2.5 \times 10^{4}$ and $1.0 \times 10^{5} \mathrm{cfu}$ $\mathrm{mL}^{-1}$; QD-ICA, $5.0 \times 10^{3}$ and $2.5 \times 10^{4} \mathrm{cfu} \mathrm{mL}^{-1}$; FNPICA, $1.0 \times 10^{3}$ and $1.0 \times 10^{3} \mathrm{cfu} \mathrm{mL}^{-1}$; and EuNP-ICA, $5.0 \times 10^{2}$ and $5.0 \times 10^{2} \mathrm{cfu} \mathrm{mL}^{-1}$. The FNP-ICA and EuNP-ICA showed better tolerance to the milk matrix than the GNP-ICA and QD-ICA. The improved tolerance was attributed to the good mechanical and chemical stability of the FNP and EuNP (Ma et al., 2009; Saraf et al., 2015; Wang et al., 2016). The chemical and colloidal instability of QD in biological environments adversely affected the sensitivity of QD-ICA (Aldana et al., 2001). The FNP-ICA and EuNP-ICA may have satisfactory tolerance to other matrices.

\section{CONCLUSIONS}

We developed 4 nanoparticle-based ICA for the quantitative and sensitive detection of E. coli O157:H7. All 4 ICA showed practical quantitative detection under optimal conditions. The EuNP-ICA showed the highest sensitivity, and the FNP-ICA required the least amount of $\mathrm{mAb}$ and had the best CV. Additionally, the FNP-ICA and EuNP-ICA had wider linear ranges and showed better tolerance than GNP-ICA and QDICA in milk samples. The FNP-ICA and EuNP-ICA have potential practical applications for the detection of pathogens in milk.

Table 2. Recoveries of Escherichia coli O157:H7 detected by the immunochromatographic assays (ICA) ${ }^{1}$

\begin{tabular}{lcccc}
\hline \multirow{2}{*}{ ICA } & $\begin{array}{c}\text { Spiked concentration } \\
\left(\mathrm{cfu} \cdot \mathrm{mL}^{-1}\right)\end{array}$ & $\begin{array}{c}\text { Detected } \\
\left(\mathrm{cfu} \cdot \mathrm{mL}^{-1}\right)\end{array}$ & Recovery $^{3}(\%)$ & CV $(\%)$ \\
\hline GNP-ICA & $5.0 \times 10^{4}$ & 44,450 & 88.9 & 15.8 \\
& $1.0 \times 10^{5}$ & 97,147 & 97.1 & 7.6 \\
QD-ICA & $2.5 \times 10^{5}$ & 313,365 & 125.3 & 7.4 \\
& $5.0 \times 10^{4}$ & 58,865 & 117.7 & 12.6 \\
FNP-ICA & $1.0 \times 10^{5}$ & 114,057 & 114.1 & 18.6 \\
& $2.5 \times 10^{5}$ & 234,737 & 93.9 & 10.4 \\
EuNP-ICA & $1.0 \times 10^{4}$ & 10,038 & 100.4 & 4.0 \\
& $2.5 \times 10^{4}$ & 29,859 & 119.4 & 7.8 \\
& $5.0 \times 10^{4}$ & 58,295 & 116.6 & 6.9 \\
& $1.0 \times 10^{4}$ & 8,334 & 83.3 & 8.3 \\
\hline
\end{tabular}

${ }^{1} \mathrm{GNP}=$ gold nanoparticle; $\mathrm{QD}=$ quantum dot; FNP $=$ fluorescent nanoparticle; EuNP $=$ europium $(\mathrm{III})$ chelate nanoparticle.

${ }^{2}$ Mean value of 3 replicates at each spiked concentration.

${ }^{3}$ Recovery $=($ detected concentration/spiked concentration $) \times 100$. 

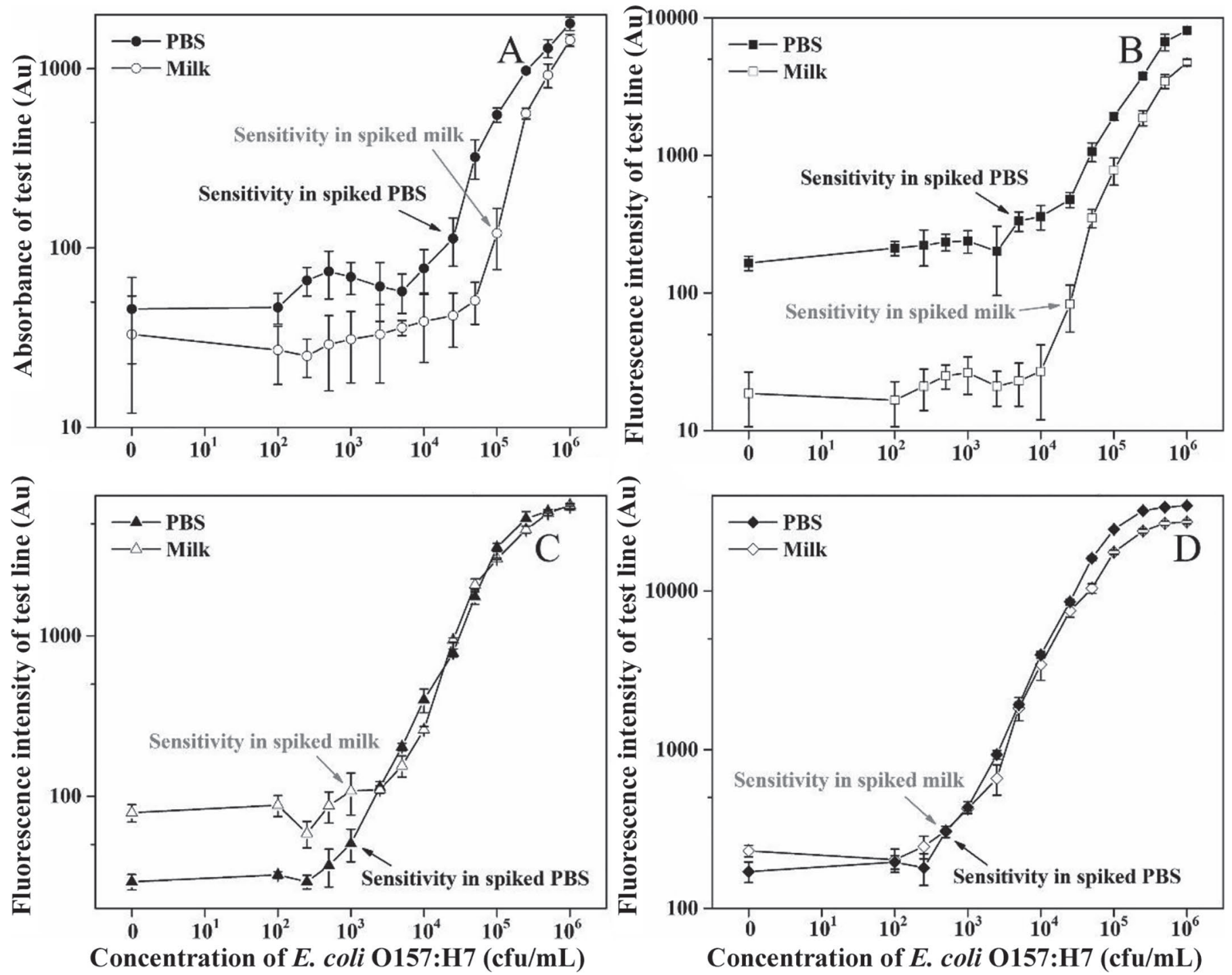

Figure 7. Influence of the milk matrix on the sensitivity of (A) gold nanoparticle-based immunochromatographic assay (GNP-ICA); (B) quantum dot-based ICA (QD-ICA); (C) fluorescent nanoparticle-based ICA (FNP-ICA); and (D) europium (III) chelate nanoparticle-based CA (EuNP-ICA). Vertical bars indicate SD $(\mathrm{n}=3)$.

\section{ACKNOWLEDGMENTS}

We are grateful to the Earmarked Fund for Jiangxi Agriculture Research System (JXARS-03); the Jiangxi Science and Technology Project (2011BBG70010-3); and the Jiangxi Education Bureau Technology Put into Use Project (KJLD13009).

\section{REFERENCES}

Aldana, J., Y. A. W. And, and X. Peng. 2001. Photochemical instability of CdSe nanocrystals coated by hydrophilic thiols. J. Am. Chem. Soc. 123:8844-8850.

Barreiros dos Santos, M., J. P. Agusil, B. Prieto-Simon, C. Sporer, V. Teixeira, and J. Samitier. 2013. Highly sensitive detection of pathogen Escherichia coli O157:H7 by electrochemical impedance spectroscopy. Biosens. Bioelectron. 45:174-180.

Bian, X., F. Jing, G. Li, X. Fan, C. Jia, H. Zhou, Q. Jin, and J. Zhao. 2015. A microfluidic droplet digital PCR for simultaneous detection of pathogenic Escherichia coli $\mathrm{O} 157$ and Listeria monocytogenes. Biosens. Bioelectron. 74:770-777.

Brichta-Harhay, D. M., T. M. Arthur, J. M. Bosilevac, M. N. Guerini, N. Kalchayanand, and M. Koohmaraie. 2007. Enumeration of Salmonella and Escherichia coli O157:H7 in ground beef, cattle carcass, hide and faecal samples using direct plating methods. J. Appl. Microbiol. 103:1657-1668.

Cui, X., Y. Huang, J. Wang, L. Zhang, Y. Rong, W. Lai, and T. Chen. 2015. A remarkable sensitivity enhancement in a gold nanoparticle-based lateral flow immunoassay for the detection of Escherichia coli O157:H7. RSC Advances 5:45092-45097.

Franco, M. M. J., A. C. Paes, M. G. Ribeiro, J. C. de Figueiredo Pantoja, A. C. B. Santos, M. Miyata, C. Q. F. Leite, R. G. Motta, and F. J. P. Listoni. 2013. Occurrence of mycobacteria in bovine milk samples from both individual and collective bulk tanks at farms 
and informal markets in the southeast region of Sao Paulo, Brazil. BMC Vet. Res. 9:85.

Guimarães, F. F., M. P. Manzi, S. F. Joaquim, V. B. Richini-Pereira, and H. Langoni. 2017. Short communication: Outbreak of methicillin-resistant Staphylococcus aureus (MRSA)-associated mastitis in a closed dairy herd. J. Dairy Sci. 100:726-730.

Hildebrandt, N., C. M. Spillmann, W. R. Algar, T. Pons, M. H. Stewart, E. Oh, K. Susumu, S. A. Diaz, J. B. Delehanty, and I. L. Medintz. 2017. Energy transfer with semiconductor quantum dot bioconjugates: A versatile platform for biosensing, energy harvesting, and other developing applications. Chem. Rev.117:536-711.

Jiawang, F., H. Xiaoyan, H. Xiaojie, W. Xiaoyu, T. Shiming, K. Xiaoshan, L. Danlin, and C. Xiaowei. 2016. Study on rapid detection of seven common foodborne pathogens by gene chip. Afr. J. Microbiol. Res. 10:285-291.

Ju, Q., M. O. Noor, and U. J. Krull. 2016. Paper-based biodetection using luminescent nanoparticles. Analyst 141:2838-2860.

Labeau, O., P. Tamarat, and B. Lounis. 2003. Temperature dependence of the luminescence lifetime of single CdSe/ZnS quantum dots. Phys. Rev. Lett. 90:257404.

Lai, X. H., R. L. Liang, T. C. Liu, Z. N. Dong, Y. S. Wu, and L. H. Li. 2016. A fluorescence immunochromatographic assay using europium (III) chelate microparticles for rapid, quantitative and sensitive detection of creatine kinase MB. J. Fluoresc. 26:987-996.

Li, C., W. Luo, H. Xu, Q. Zhang, H. Xu, Z. P. Aguilar, W. Lai, H. Wei, and Y. Xiong. 2013. Development of an immunochromatographic assay for rapid and quantitative detection of clenbuterol in swine urine. Food Contr. 34:725-732.

Liu, C., Q. Jia, C. Yang, R. Qiao, L. Jing, L. Wang, C. Xu, and M. Gao. 2011. Lateral flow immunochromatographic assay for sensitive pesticide detection by using $\mathrm{Fe}_{3} \mathrm{O}_{4}$ nanoparticle aggregates as color reagents. Anal. Chem. 83:6778-6784.

Liu, D., Y. Huang, M. Chen, S. Wang, K. Liu, and W. Lai. 2015. Rapid detection method for aflatoxin B1 in soybean sauce based on fluorescent microspheres probe. Food Contr. 50:659-662.

Liu, X., Y. Guan, S. Cheng, Y. Huang, Q. Yan, J. Zhang, G. Huang, J. Zheng, and T. Liu. 2016. Development of a highly sensitive lateral immunochromatographic assay for rapid detection of Vibrio parahaemolyticus. J. Microbiol. Methods 131:78-84.

Ma, D. L., A. J. Kell, S. Tan, Z. J. Jakubek, and B. Simard. 2009. Photophysical properties of dye-doped silica nanoparticles bearing different types of dye-silica interactions. J. Phys. Chem. C 113:15974-15981.

Morales-Narváez, E., T. Naghdi, E. Zor, and A. Merkoci. 2015. Photoluminescent lateral-flow immunoassay revealed by graphene oxide: Highly sensitive paper-based pathogen detection. Anal. Chem. 87:8573-8577.

Oh, S. W., Y. M. Kim, H. J. Kim, S. J. Kim, J. S. Cho, and E. Y. Choi. 2009. Point-of-care fluorescence immunoassay for prostate specific antigen. Clin. Chim. Acta 406:18-22.

Preechakasedkit, P., K. Pinwattana, W. Dungchai, W. Siangproh, W. Chaicumpa, P. Tongtawe, and O. Chailapakul. 2012. Development of a one-step immunochromatographic strip test using gold nanoparticles for the rapid detection of Salmonella typhi in human serum. Biosens. Bioelectron. 31:562-566.

Santra, S., B. Liesenfeld, C. Bertolino, D. Dutta, Z. Cao, W. Tan, B. M. Moudgil, and R. A. Mericle. 2006. Fluorescence lifetime measure- ments to determine the core-shell nanostructure of FITC-doped silica nanoparticles: An optical approach to evaluate nanoparticle photostability. J. Lumin. 117:75-82.

Saraf, M., P. Kumar, G. Kedawat, J. Dwivedi, S. A. Vithayathil, N. Jaiswal, B. A. Kaipparettu, and B. K. Gupta. 2015. Probing highly 1uminescent europium-doped 1anthanum orthophosphate nanorods for strategic applications. Inorg. Chem. 54:2616-2625.

Shan, S., D. Liu, Q. Guo, S. Wu, R. Chen, K. Luo, L. Hu, Y. Xiong, and W. Lai. 2016. Sensitive detection of Escherichia coli O157:H7 based on cascade signal amplification in ELISA. J. Dairy Sci. 99:7025-7032

Taponen, S., E. Liski, A. M. Heikkilä, and S. Pyörälä. 2017. Factors associated with intramammary infection in dairy cows caused by coagulase-negative staphylococci, Staphylococcus aureus, Streptococcus uberis, Streptococcus dysgalactiae, Corynebacterium bovis, or Escherichia coli. J. Dairy Sci. 100:493-503.

Ueda, S., M. Iwase, and Y. Kuwabara. 2013. Evaluation of immunochromatography for the rapid and specific identification of Listeria monocytogenes from food. Biocontrol Sci. 18:157-161.

Wang, M., H. Ye, L. You, and X. Chen. 2016. A supramolecular sensor array using lanthanide-doped nanoparticles for sensitive detection of glyphosate and proteins. ACS Appl. Mater. Interfaces 8:574-581.

Wang, Y., Z. Ye, C. Si, and Y. Ying. 2013. Monitoring of Escherichia coli $\mathrm{O} 157: \mathrm{H7}$ in food samples using lectin based surface plasmon resonance biosensor. Food Chem. 136:1303-1308.

World Health Organization. 2015. Food safety. Accessed Oct. 10, 2016. http://www.who.int/mediacentre/factsheets/fs399/en/.

Xu, F., D. Xu, X. Ming, H. Y. Xu, B. Li, P. Li, Z. P. Aguilar, T. T. Cheng, X. L. Wu, and H. Wei. 2013. Quantum dot-based immunochromatography test strip for rapid detection of Campylobacter jejuni. J. Nanosci. Nanotechnol. 13:4552-4559.

Yang, Q., J. Zhu, F. Ma, P. Li, L. Zhang, W. Zhang, X. Ding, and Q. Zhang. 2016. Quantitative determination of major capsaicinoids in serum by ELISA and time-resolved fluorescent immunoassay based on monoclonal antibodies. Biosens. Bioelectron. 81:229-235.

Zhang, F., M. Zou, Y. Chen, J. Li, Y. Wang, X. Qi, and Q. Xue. 2014a. Lanthanide-labeled immunochromatographic strips for the rapid detection of Pantoea stewartii ssp. stewartii. Biosens. Bioelectron. 51:29-35.

Zhang, H., L. Ma, L. Ma, M. Z. Hua, S. Wang, and X. Lu. 2017. Rapid detection of methicillin-resistant Staphylococcus aureus in pork using a nucleic acid-based lateral flow immunoassay. Int. J. Food Microbiol. 243:64-69.

Zhang, J., N. Prabhakar, T. Näreoja, and J. M. Rosenholm. 2014b. Semiconducting polymer encapsulated mesoporous silica particles with conjugated europium complexes: Toward enhanced 1uminescence under aqueous conditions. ACS Appl. Mater. Interfaces 6:19064-19074.

Zhang, L., Y. Huang, J. Wang, Y. Rong, W. Lai, J. Zhang, and T. Chen. 2015. Hierarchical flowerlike gold nanoparticles 1abeled immunochromatography test strip for highly sensitive detection of Escherichia coli O157:H7. Langmuir 31:5537-5544.

Zhou, J., K. Zhu, F. Xu, W. Wang, H. Jiang, Z. Wang, and S. Ding. 2014. Development of a microsphere-based fluorescence immunochromatographic assay for monitoring lincomycin in milk, honey, beef, and swine urine. J. Agric. Food Chem. 62:12061-12066. 